Article

\title{
Correlation Coefficient between Dynamic Single Valued Neutrosophic Multisets and Its Multiple Attribute Decision-Making Method
}

\author{
Jun Ye \\ Department of Electrical and Information Engineering, Shaoxing University, 508 Huancheng West Road, \\ Shaoxing 312000, China; yehjun@aliyun.com; Tel.: +86-575-8832-7323 \\ Academic Editor: Willy Susilo \\ Received: 7 March 2017; Accepted: 5 April 2017; Published: 7 April 2017
}

\begin{abstract}
Based on dynamic information collected from different time intervals in some real situations, this paper firstly proposes a dynamic single valued neutrosophic multiset (DSVNM) to express dynamic information and operational relations of DSVNMs. Then, a correlation coefficient between DSVNMs and a weighted correlation coefficient between DSVNMs are presented to measure the correlation degrees between DSVNMs, and their properties are investigated. Based on the weighted correlation coefficient of DSVNMs, a multiple attribute decision-making method is established under a DSVNM environment, in which the evaluation values of alternatives with respect to attributes are collected from different time intervals and are represented by the form of DSVNMs. The ranking order of alternatives is performed through the weighted correlation coefficient between an alternative and the ideal alternative, which is considered by the attribute weights and the time weights, and thus the best one(s) can also be determined. Finally, a practical example shows the application of the proposed method.
\end{abstract}

Keywords: dynamic single valued neutrosophic multiset; correlation coefficient; decision-making

\section{Introduction}

The theory of neutrosophic sets presented by Smarandache [1] is a powerful technique to handle incomplete, indeterminate and inconsistent information in the real world. As the generalization of a classic set, fuzzy set [2], intuitionistic fuzzy set [3], and interval-valued intuitionistic fuzzy set [4], a neutrosophic set can independently express a truth-membership degree, an indeterminacy-membership degree, and a falsity-membership degree. All the factors described by the neutrosophic set are very suitable for human thinking due to the imperfection of knowledge that humans receive or observe from the external world. For example, consider the given proposition "Movie X would be a hit." In this situation, the human brain certainly cannot generate precise answers in terms of yes or no, because indeterminacy is the sector of unawareness of a proposition's value between truth and falsehood. Obviously, the neutrosophic components are very suitable for the representation of indeterminate and inconsistent information.

A neutrosophic set $A$ in a universal set $X$ is characterized by a truth-membership function $\mu_{A}(x)$, an indeterminacy-membership function $\tau_{A}(x)$ and a falsity-membership function $v_{A}(x)$. The functions $\mu_{A}(x), \tau_{A}(x), v_{A}(x)$ in $X$ are real standard or nonstandard subsets of $]^{-} 0,1^{+}\left[\text {, such that } \mu_{A}(x): X \rightarrow\right]^{-} 0$, $1^{+}\left[, \tau_{A}(x): X \rightarrow\right]^{-} 0,1^{+}\left[\text {, and } v_{A}(x): X \rightarrow\right]^{-} 0,1^{+}$[. Then, the sum of $\mu_{A}(x), \tau_{A}(x)$ and $v_{A}(x)$ is no restriction, i.e., $-0 \leq \sup \mu_{A}(x)+\sup \tau_{A}(x)+\sup v_{A}(x) \leq 3^{+}$. Since the functions $\mu_{A}(x), \tau_{A}(x)$ and $v_{A}(x)$ are defined in the nonstandard interval $]^{-} 0,1^{+}[$, it is difficult to apply the neutrosophic set to science and engineering fields. So, we can constrain the functions $\mu_{A}(x), \tau_{A}(x)$ and $v_{A}(x)$ in the real standard interval $[0,1]$ to easily apply to real situations. Thus, Wang et al. $[5,6]$ defined a single 
valued neutrosophic set (SVNS) and an interval neutrosophic set (INS), which are the subclasses of the neutrosophic set. SVNSs and INSs are more suitable for the representation of indeterminate and inconsistent information in science and engineering applications.

Recently, neutrosophic sets have become research topics in engineering areas, such as decision-making [7-17], clustering analysis [18,19], and image processing [20-22]. By means of combining neutrosophic sets with other sets, some extensions of them have been recently developed, such as neutrosophic soft sets [23-25], single valued neutrosophic hesitant fuzzy sets [26,27], interval neutrosophic hesitant sets [28], interval neutrosophic linguistic sets [29], single valued neutrosophic linguistic sets [30]. Moreover, these have been successfully applied in decision-making. Furthermore, multi-valued neutrosophic sets for medical diagnosis [31] and decision-making [32,33] were proposed under multi-valued neutrosophic environments. Neutrosophic refined sets and bipolar neutrosophic refined sets were also developed for solving medical diagnosis problems [34-37]. Normal neutrosophic fuzzy numbers were presented to handle multiple attribute decision-making problems with normal neutrosophic fuzzy information [38,39].

In general, all of the above studies have significantly advanced in the theory and applications of various neutrosophic sets. However, the aforementioned neutrosophic information is collected all at once, at the same time, which is also called static information. But, as for some complex problems in real situations, such as some complex decision-making problems, moving image processing problems, complex medical diagnosis problems, and personnel dynamic examination, we have to consider these dynamic problems in different time intervals. In these cases, how can we express the dynamic problems? One solution is to express dynamic information collected from different time intervals by dynamic single valued neutrosophic multisets. To do so, the main aims of this paper are: (1) to propose a dynamic single valued neutrosophic multiset (DSVNM) as a better tool for expressing dynamic information of dynamic problems; (2) to develop correlation coefficients between DSVNMs for measuring the correlation degree between two DSVNMs; and (3) to apply the correlation coefficient to multiple attribute decision-making problems with DSVNM information.

The rest of the article is organized as follows. Section 2 introduces some concepts and basic operations of SVNSs and a correlation coefficient between SVNSs. Section 3 presents a DSVNM and its basic operational relations. A correlation coefficient between DSVNMs and a weighted correlation coefficient between DSVNMs are proposed and their properties are investigated in Section 4. Section 5 develops a multiple attribute decision-making method using the weighted correlation coefficient of DSVNMs under DSVNM environment. In Section 6, a practical example of a decision-making problem concerning investment alternatives is provided to demonstrate the applications of the proposed decision-making method under DSVNM environment. Conclusions and further research are given in Section 7.

\section{Some Concepts of SVNSs}

Smarandache [1] originally presented the concept of a neutrosophic set from a philosophical point of view. To easily use it in real applications, Wang et al. [6] introduced the concept of SVNS as a subclass of the neutrosophic set and gave the following definition.

Definition 1 [6]. Let $X$ be a universal set. A SVNS A in X is characterized by a truth-membership function $\mu_{A}(x)$, an indeterminacy-membership function $\tau_{A}(x)$ and a falsity-membership function $v_{A}(x)$. Then, a SVNS A can be denoted by the following form:

$$
A=\left\{\left\langle x, \mu_{A}(x), \tau_{A}(x), v_{A}(x)\right\rangle \mid x \in X\right\}
$$

where $\mu_{A}(x), \tau_{A}(x), v_{A}(x) \in[0,1]$ for each $x$ in $X$. Therefore, the sum of $\mu_{A}(x), \tau_{A}(x)$ and $v_{A}(x)$ satisfies the condition $0 \leq \mu_{A}(x)+\tau_{A}(x)+v_{A}(x) \leq 3$. 
For two SVNSs $A=\left\{\left\langle x, \mu_{A}(x), \tau_{A}(x), v_{A}(x)\right\rangle \mid x \in X\right\}$ and $B=\left\{\left\langle x, \mu_{B}(x), \tau_{B}(x), v_{B}(x)\right\rangle \mid x \in X\right\}$, there are the following relations [6]:

(1) Complement: $A^{c}=\left\{\left\langle x, v_{A}(x), 1-\tau_{A}(x), \mu_{A}(x)\right\rangle \mid x \in X\right\}$;

(2) Inclusion: $A \subseteq B$ if and only if $\mu_{A}(x) \leq \mu_{B}(x), \tau_{A}(x) \geq \tau_{B}(x), v_{A}(x) \geq v_{B}(x)$ for any $x$ in $X$;

(3) Equality: $A=B$ if and only if $A \subseteq B$ and $B \subseteq A$;

(4) Union: $A \cup B=\left\{\left\langle x, \mu_{A}(x) \vee \mu_{B}(x), \tau_{A}(x) \wedge \tau_{B}(x), v_{A}(x) \wedge v_{B}(x)\right\rangle \mid x \in X\right\}$;

(5) Intersection: $A \cap B=\left\{\left\langle x, \mu_{A}(x) \wedge \mu_{B}(x), \tau_{A}(x) \vee \tau_{B}(x), v_{A}(x) \vee v_{B}(x)\right\rangle \mid x \in X\right\}$;

(6) Addition: $A+B=\left\{\left\langle x, \mu_{A}(x)+\mu_{B}(x)-\mu_{A}(x) \mu_{B}(x), \tau_{A}(x) \tau_{B}(x), v_{A}(x) v_{B}(x)\right\rangle \mid x \in X\right\}$;

(7) Multiplication:

$A \times B=\left\{\left\langle x, \mu_{A}(x) \mu_{B}(x), \tau_{A}(x)+\tau_{B}(x)-\tau_{A}(x) \tau_{B}(x), v_{A}(x)+v_{B}(x)-v_{A}(x) v_{B}(x)\right\rangle \mid x \in X\right\}$.

Then, Ye [8] defined a correlation coefficient between $A$ and $B$ as follows:

$$
R(A, B)=\frac{\sum_{j=1}^{n}\left[\mu_{A}\left(x_{j}\right) \mu_{B}\left(x_{j}\right)+\tau_{A}\left(x_{j}\right) \tau_{B}\left(x_{j}\right)+v_{A}\left(x_{j}\right) v_{B}\left(x_{j}\right)\right]}{\sqrt{\sum_{j=1}^{n}\left[\left(\mu_{A}\left(x_{j}\right)\right)^{2}+\left(\tau_{A}\left(x_{j}\right)\right)^{2}+\left(v_{A}\left(x_{j}\right)\right)^{2}\right]} \sqrt{\sum_{j=1}^{n}\left[\left(\mu_{B}\left(x_{j}\right)\right)^{2}+\left(\tau_{B}\left(x_{j}\right)\right)^{2}+\left(v_{B}\left(x_{j}\right)\right)^{2}\right]}}
$$

The correlation coefficient between $A$ and $B$ satisfies the following properties [8]:

(P1) $0 \leq R(A, B) \leq 1$;

(P2) $R(A, B)=1$ if $A=B$;

(P3) $R(A, B)=R(B, A)$.

\section{Dynamic Single Valued Neutrosophic Multiset}

This section proposes a dynamic single valued neutrosophic multiset and its operational relations.

Definition 2. Let $X$ be a nonempty set with generic elements in $X$ denoted by $x$, and $t=\left\{t_{1}, t_{2}\right.$, $\left.\ldots, t_{q}\right\}$ be a time sequence. A dynamic single valued neutrosophic multiset (DSVNM) A(t) collected from $X$ and $t$ is characterized by a truth-membership time sequence $\left(\mu_{A}\left(t_{1}, x\right), \mu_{A}\left(t_{2}, x\right), \ldots, \mu_{A}\left(t_{q}, x\right)\right)$, an indeterminacy-membership time sequence $\left(\tau_{A}\left(t_{1}, x\right), \tau_{A}\left(t_{2}, x\right), \ldots, \tau_{A}\left(t_{q}, x\right)\right)$, and a falsity-membership time sequence $\left(v_{A}\left(t_{1}, x\right), v_{A}\left(t_{2}, x\right), \ldots, v_{A}\left(t_{q}, x\right)\right)$ such that $\mu_{A}\left(t_{k}, x\right): X \rightarrow R, \tau_{A}\left(t_{k}, x\right): X \rightarrow R, v_{A}\left(t_{k}, x\right): X \rightarrow R$ for $t_{k} \in t$ and $x \in X$, where $R$ is the set of all real numbers in the real unit interval $[0,1]$. Then, a DSVNM A(t) is denoted by:

$$
A(t)=\left\{\left\langle\begin{array}{c}
x,\left(\mu_{A}\left(t_{1}, x\right), \mu_{A}\left(t_{2}, x\right), \ldots, \mu_{A}\left(t_{q}, x\right)\right), \\
\left(\tau_{A}\left(t_{1}, x\right), \tau_{A}\left(t_{2}, x\right), \ldots, \tau_{A}\left(t_{q}, x\right)\right), \\
\left(v_{A}\left(t_{1}, x\right), v_{A}\left(t_{2}, x\right), \ldots, v_{A}\left(t_{q}, x\right)\right)
\end{array}\right\rangle \mid t_{k} \in t, x \in X\right\}
$$

Obviously, the sum of $\mu_{A}\left(t_{k}, x\right), \tau_{A}\left(t_{k}, x\right), v_{A}\left(t_{k}, x\right) \in[0,1]$ satisfies the condition $0 \leq \mu_{A}\left(t_{k}, x\right)+\tau_{A}\left(t_{k}, x\right)$ $+v_{A}\left(t_{k}, x\right) \leq 3$ for $t_{k} \in t$ and $x \in X$ and $k=1,2, \ldots, q$.

For convenience, a DSVNM $A(t)$ can be denoted by the following simplified form:

$$
A(t)=\left\{\left\langle x, \mu_{A}\left(t_{k}, x\right), \tau_{A}\left(t_{k}, x\right), v_{A}\left(t_{k}, x\right)\right\rangle \mid t_{k} \in t, x \in X\right\}
$$

For example, a DSVNM in the time sequence $t=\left\{t_{1}, t_{2}, t_{3}\right\}$ and a universal set $X=\left\{x_{1}, x_{2}\right\}$ is given as:

$A(t)=\left\{<x_{1},(0.3,0.2,0.5),(0.4,0.3,0.5),(0.6,0.8,0.9)>,<x_{2},(0.4,0.4,0.3),(0.1,0.2,0.1),(0.3,0.5,0.4)>\right\}$ 
Definition 3. Let $A(t)=\left\{\left\langle x, \mu_{A}\left(t_{k}, x\right), \tau_{A}\left(t_{k}, x\right), v_{A}\left(t_{k}, x\right)\right\rangle \mid t_{k} \in t, x \in X\right\}$ and $B(t)=\left\{\left\langle x, \mu_{B}\left(t_{k}, x\right)\right.\right.$, $\left.\left.\tau_{B}\left(t_{k}, x\right), v_{B}\left(t_{k}, x\right)\right\rangle \mid t_{k} \in t, x \in X\right\}$ be any two DSVNMs in $t=\left\{t_{1}, t_{2}, \ldots, t_{q}\right\}$ and $X$. Then, there are the following relations:

(1) Inclusion: $A(t) \subseteq B(t)$ if and only if $\mu_{A}\left(t_{k}, x\right) \leq \mu_{B}\left(t_{k}, x\right), \tau_{A}\left(t_{k}, x\right) \geq \tau_{B}\left(t_{k}, x\right), v_{A}\left(t_{k}, x\right) \geq v_{B}\left(t_{k}, x\right)$ for $k=1,2, \ldots$, and $x \in X$

(2) Equality: $A(t)=B(t)$ if and only if $A(t) \subseteq B(t)$ and $B(t) \subseteq A(t)$;

(3) Complement: $A^{c}(t)=\left\{\left\langle x, v_{A}\left(t_{k}, x\right),\left(1-\tau_{A}\left(t_{k}, x\right)\right), \mu_{A}\left(t_{k}, x\right)\right\rangle \mid t_{k} \in t, x \in X\right\}$;

(4) Union:

$A(t) \cup B(t)=\left\{\left\langle x, \mu_{A}\left(t_{k}, x\right) \vee \mu_{B}\left(t_{k}, x\right), \tau_{A}\left(t_{k}, x\right) \wedge \tau_{B}\left(t_{k}, x\right), v_{A}\left(t_{k}, x\right) \wedge v_{B}\left(t_{k}, x\right)\right\rangle \mid t_{k} \in t, x \in X\right\} ;$

(5) Intersection:

$A(t) \cap B(t)=\left\{\left\langle x, \mu_{A}\left(t_{k}, x\right) \wedge \mu_{B}\left(t_{k}, x\right), \tau_{A}\left(t_{k}, x\right) \vee \tau_{B}\left(t_{k}, x\right), v_{A}\left(t_{k}, x\right) \vee v_{B}\left(t_{k}, x\right)\right\rangle \mid t_{k} \in t, x \in X\right\}$.

For convenience, we can use $a(t)=\left\langle\left(\mu\left(t_{1}, x\right), \mu\left(t_{2}, x\right), \ldots, \mu\left(t_{q}, x\right)\right),\left(\tau\left(t_{1}, x\right), \tau\left(t_{2}, x\right), \ldots, \tau\left(t_{q}, x\right)\right)\right.$, $\left.\left(v\left(t_{1}, x\right), v\left(t_{2}, x\right), \ldots, v\left(t_{q}, x\right)\right)\right\rangle$ to represent a basic element in a DSVNM $A(t)$ and call it a dynamic single valued neutrosophic multiset element (DSVNME).

Definition 4. Let $a_{1}(t)=\left\langle\left(\mu_{1}\left(t_{1}, x\right), \mu_{1}\left(t_{2}, x\right), \ldots, \mu_{1}\left(t_{q}, x\right)\right),\left(\tau_{1}\left(t_{1}, x\right), \tau_{1}\left(t_{2}, x\right), \ldots, \tau_{1}\left(t_{q}, x\right)\right),\left(v_{1}\left(t_{1}, x\right)\right.\right.$, $\left.\left.v_{1}\left(t_{2}, x\right), \ldots, v_{1}\left(t_{q}, x\right)\right)\right\rangle$ and $a_{2}(t)=\left\langle\left(\mu_{2}\left(t_{1}, x\right), \mu_{2}\left(t_{2}, x\right), \ldots, \mu_{2}\left(t_{q}, x\right)\right),\left(\tau_{2}\left(t_{1}, x\right), \tau_{2}\left(t_{2}, x\right), \ldots, \tau_{2}\left(t_{q}, x\right)\right)\right.$, $\left.\left(v_{2}\left(t_{1}, x\right), v_{2}\left(t_{2}, x\right), \ldots, v_{2}\left(t_{q}, x\right)\right)\right\rangle$ be two DSVNMEs and $\lambda \geq 0$, then the operational rules of DSVNMES are defined as follows:

$$
\begin{aligned}
& \left(\mu_{1}\left(t_{1}, x\right)+\mu_{2}\left(t_{1}, x\right)-\mu_{1}\left(t_{1}, x\right) \mu_{2}\left(t_{1}, x\right),\right. \\
& a_{1}(t) \oplus a_{2}(t)=\left\langle\begin{array}{c}
\mu_{1}\left(t_{2}, x\right)+\mu_{2}\left(t_{2}, x\right)-\mu_{1}\left(t_{2}, x\right) \mu_{2}\left(t_{2}, x\right), \\
\left.\ldots, \mu_{1}\left(t_{q}, x\right)+\mu_{2}\left(t_{q}, x\right)-\mu_{1}\left(t_{q}, x\right) \mu_{2}\left(t_{q}, x\right)\right), \\
\left(\tau_{1}\left(t_{1}, x\right) \tau_{2}\left(t_{1}, x\right), \tau_{1}\left(t_{2}, x\right) \tau_{2}\left(t_{2}, x\right), \ldots, \tau_{1}\left(t_{q}, x\right) \tau_{2}\left(t_{q}, x\right)\right),
\end{array}\right\rangle \\
& \left(v_{1}\left(t_{1}, x\right) v_{2}\left(t_{1}, x\right), v_{1}\left(t_{2}, x\right) v_{2}\left(t_{2}, x\right), \ldots, v_{1}\left(t_{q}, x\right) v_{2}\left(t_{q}, x\right)\right) \\
& \left(\mu_{1}\left(t_{1}, x\right) \mu_{2}\left(t_{1}, x\right), \mu_{1}\left(t_{2}, x\right) \mu_{2}\left(t_{2}, x\right), \ldots, \mu_{1}\left(t_{q}, x\right) \mu_{2}\left(t_{q}, x\right)\right), \\
& \left(\tau_{1}\left(t_{1}, x\right)+\tau_{2}\left(t_{1}, x\right)-\tau_{1}\left(t_{1}, x\right) \tau_{2}\left(t_{1}, x\right),\right. \\
& a_{1}(t) \otimes a_{2}(t)=\left\langle\begin{array}{c}
\tau_{1}\left(t_{2}, x\right)+\tau_{2}\left(t_{2}, x\right)-\tau_{1}\left(t_{2}, x\right) \tau_{2}\left(t_{2}, x\right), \\
\left.\ldots, \tau_{1}\left(t_{q}, x\right)+\tau_{2}\left(t_{q}, x\right)-\tau_{1}\left(t_{q}, x\right) \tau_{2}\left(t_{q}, x\right)\right), \\
\left(v_{1}\left(t_{1}, x\right)+v_{2}\left(t_{1}, x\right)-v_{1}\left(t_{1}, x\right) v_{2}\left(t_{1}, x\right),\right.
\end{array}\right\rangle \\
& v_{1}\left(t_{2}, x\right)+v_{2}\left(t_{2}, x\right)-v_{1}\left(t_{2}, x\right) v_{2}\left(t_{2}, x\right), \\
& \left.\ldots, v_{1}\left(t_{q}, x\right)+v_{2}\left(t_{q}, x\right)-v_{1}\left(t_{q}, x\right) v_{2}\left(t_{q}, x\right)\right) \\
& \lambda a_{1}(t)=\left\langle\begin{array}{c}
\left(1-\left(1-\mu_{1}\left(t_{1}, x\right)\right)^{\lambda}, 1-\left(1-\mu_{1}\left(t_{2}, x\right)\right)^{\lambda}, \ldots, 1-\left(1-\mu_{1}\left(t_{q}, x\right)\right)^{\lambda}\right), \\
\left(\tau_{1}^{\lambda}\left(t_{1}, x\right), \tau_{1}^{\lambda}\left(t_{2}, x\right), \ldots, \tau_{1}^{\lambda}\left(t_{q}, x\right)\right),\left(v_{1}^{\lambda}\left(t_{1}, x\right), v_{1}^{\lambda}\left(t_{2}, x\right), \ldots, v_{1}^{\lambda}\left(t_{q}, x\right)\right)
\end{array}\right\rangle \\
& a_{1}^{\lambda}(t)=\left\langle\begin{array}{c}
\left(\mu_{1}^{\lambda}\left(t_{1}, x\right), \mu_{1}^{\lambda}\left(t_{2}, x\right), \ldots, \mu_{1}^{\lambda}\left(t_{q}, x\right)\right), \\
\left(1-\left(1-\tau_{1}\left(t_{1}, x\right)\right)^{\lambda}, 1-\left(1-\tau_{1}\left(t_{2}, x\right)\right)^{\lambda}, \ldots, 1-\left(1-\tau_{1}\left(t_{q}, x\right)\right)^{\lambda}\right), \\
\left(1-\left(1-v_{1}\left(t_{1}, x\right)\right)^{\lambda}, 1-\left(1-v_{1}\left(t_{2}, x\right)\right)^{\lambda}, \ldots, 1-\left(1-v_{1}\left(t_{q}, x\right)\right)^{\lambda}\right)
\end{array}\right\rangle
\end{aligned}
$$

\section{Correlation Coefficient of DSVNMs}

Correlation coefficients are usually used in science and engineering applications. They play an important role in decision-making, pattern recognition, clustering analysis, and so on. In regards to this, this section proposes a correlation coefficient of DSVNMs and a weighted correlation coefficient of DSVNMs. 
Based on DSVNMs constructed by dynamic truth-membership degrees, dynamic indeterminacymembership degrees, and dynamic falsity-membership degrees corresponding to $t=\left\{t_{1}, t_{2}, \ldots, t_{q}\right\}$, we can give the following definition of a correlation coefficient between DSVNMs.

Definition 5. Let $A(t)=\left\{\left\langle x, \mu_{A}\left(t_{k}, x\right), \tau_{A}\left(t_{k}, x\right), v_{A}\left(t_{k}, x\right)\right\rangle \mid t_{k} \in t, x \in X\right\}$ and $B(t)=\left\{\left\langle x, \mu_{B}\left(t_{k}, x\right), \tau_{B}\left(t_{k}, x\right)\right.\right.$, $\left.\left.v_{B}\left(t_{k}, x\right)\right\rangle \mid t_{k} \in t, x \in X\right\}$ be any two DSVNMs in $t=\left\{t_{1}, t_{2}, \ldots, t_{q}\right\}$ and $X=\left(x_{1}, x_{2}, \ldots, x_{n}\right)$. Then, a correlation coefficient between $A(t)$ and $B(t)$ is defined as:

$$
\begin{aligned}
& \rho(A(t), B(t))= \\
& \frac{1}{q} \sum_{k=1}^{q} \frac{\sum_{j=1}^{n}\left[\mu_{A}\left(t_{k}, x_{j}\right) \mu_{B}\left(t_{k}, x_{j}\right)+\tau_{A}\left(t_{k}, x_{j}\right) \tau_{B}\left(t_{k}, x_{j}\right)+v_{A}\left(t_{k}, x_{j}\right) v_{B}\left(t_{k}, x_{j}\right)\right]}{\left(\sqrt{\sum_{j=1}^{n}\left[\left(\mu_{A}\left(t_{k}, x_{j}\right)\right)^{2}+\left(\tau_{A}\left(t_{k}, x_{j}\right)\right)^{2}+\left(v_{A}\left(t_{k}, x_{j}\right)\right)^{2}\right]}\right)} \\
& \left.\sqrt{\sum_{j=1}^{n}\left[\left(\mu_{B}\left(t_{k}, x_{j}\right)\right)^{2}+\left(\tau_{B}\left(t_{k}, x_{j}\right)\right)^{2}+\left(v_{B}\left(t_{k}, x_{j}\right)\right)^{2}\right]}\right)
\end{aligned}
$$

Theorem 1. The correlation coefficient between A and B satisfies the following properties:

(P1) $0 \leq \rho(A(t), B(t)) \leq 1$;

(P2) $\rho(A(t), B(t))=1$ if $A(t)=B(t)$;

(P3) $\rho(A(t), B(t))=\rho(B(t), A(t))$.

Proof. (P1) The inequality $\rho(A(t), B(t)) \geq 0$ is obvious. Then, let us prove $\rho(A(t), B(t)) \leq 1$.

According to the Cauchy-Schwarz inequality:

$$
\left(x_{1} y_{1}+x_{2} y_{2}+\cdots+x_{n} y_{n}\right)^{2} \leq\left(x_{1}^{2}+x_{2}^{2}+\cdots x_{n}^{2}\right) \cdot\left(y_{1}^{2}+y_{2}^{2}+\cdots y_{n}^{2}\right)
$$

where $\left(x_{1}, x_{2}, \ldots, x_{n}\right) \in R^{n}$ and $\left(y_{1}, y_{2}, \ldots, y_{n}\right) \in R^{n}$. Then, we can obtain the following inequality:

$$
\left(x_{1} y_{1}+x_{2} y_{2}+\cdots+x_{n} y_{n}\right) \leq \sqrt{\left(x_{1}^{2}+x_{2}^{2}+\cdots x_{n}^{2}\right)} \cdot \sqrt{\left(y_{1}^{2}+y_{2}^{2}+\cdots y_{n}^{2}\right)}
$$

According to the above inequality, there is the following inequality:

$$
\begin{gathered}
\sum_{j=1}^{n} \mu_{A}\left(t_{k}, x_{j}\right) \sum_{j=1}^{n} \mu_{B}\left(t_{k}, x_{j}\right)+\sum_{j=1}^{n} \tau_{A}\left(t_{k}, x_{j}\right) \sum_{j=1}^{n} \tau_{B}\left(t_{k}, x_{j}\right)+\sum_{j=1}^{n} v_{A}\left(t_{k}, x_{j}\right) \sum_{j=1}^{n} v_{B}\left(t_{k}, x_{j}\right) \leq \\
\sqrt{\sum_{j=1}^{n}\left(\mu_{A}\left(t_{k}, x_{j}\right)\right)^{2}+\sum_{j=1}^{n}\left(\tau_{A}\left(t_{k}, x_{j}\right)\right)^{2}+\sum_{j=1}^{n}\left(v_{A}\left(t_{k}, x_{j}\right)\right)^{2}} \sqrt{\sum_{j=1}^{n}\left(\mu_{B}\left(t_{k}, x_{j}\right)\right)^{2}+\sum_{j=1}^{n}\left(\tau_{B}\left(t_{k}, x_{j}\right)\right)^{2}+\sum_{j=1}^{n}\left(v_{B}\left(t_{k}, x_{j}\right)\right)^{2}}
\end{gathered}
$$

Hence, there is:

$$
\begin{gathered}
\sum_{j=1}^{n}\left[\mu_{A}\left(t_{k}, x_{j}\right) \mu_{B}\left(t_{k}, x_{j}\right)+\tau_{A}\left(t_{k}, x_{j}\right) \tau_{B}\left(t_{k}, x_{j}\right)+v_{A}\left(t_{k}, x_{j}\right) v_{B}\left(t_{k}, x_{j}\right)\right] \leq \\
\sqrt{\sum_{j=1}^{n}\left[\left(\mu_{A}\left(t_{k}, x_{j}\right)\right)^{2}+\left(\tau_{A}\left(t_{k}, x_{j}\right)\right)^{2}+\left(v_{A}\left(t_{k}, x_{j}\right)\right)^{2}\right]} \sqrt{\sum_{j=1}^{n}\left[\left(\mu_{B}\left(t_{k}, x_{j}\right)\right)^{2}+\left(\tau_{B}\left(t_{k}, x_{j}\right)\right)^{2}+\left(v_{B}\left(t_{k}, x_{j}\right)\right)^{2}\right]}
\end{gathered}
$$

From Equation (2), we have $\rho(A(t), B(t)) \leq 1$. Thus, $0 \leq \rho(A(t), B(t)) \leq 1$.

(P2) $A(t)=B(t) \Rightarrow \mu_{A}\left(t_{k}, x_{j}\right)=\mu_{B}\left(t_{k}, x_{j}\right), \tau_{A}\left(t_{k}, x_{j}\right)=\tau_{B}\left(t_{k}, x_{j}\right)$, and $v_{A}\left(t_{k}, x_{j}\right)=v_{B}\left(t_{k}, x_{j}\right)$ for $t_{k} \in t$ and $x_{j} \in X \Rightarrow \rho(A(t), B(t))=1$.

(P3) It is straightforward.

In practical applications, we should consider different weights for each element $x_{j}(j=1,2, \ldots, n)$ in $X$ and each time $t_{k}(k=1,2, \ldots, q)$ in $t$. Then, let $w=\left(w_{1}, w_{2}, \ldots, w_{n}\right)^{\mathrm{T}}$ be the weighting vector of $x_{j}(j=1,2, \ldots, n)$ with $w_{j} \geq 0$ and $\sum_{j=1}^{n} w_{j}=1$ and $\omega(t)=\left(\omega\left(t_{1}\right), \omega\left(t_{2}\right), \ldots, \omega\left(t_{q}\right)\right)^{\mathrm{T}}$ be the weighting 
vector of $t_{k}(k=1,2, \ldots, q)$ with $\omega\left(t_{k}\right) \geq 0$ and $\sum_{k=1}^{q} \omega\left(t_{k}\right)=1$. Hence, we further extend the correlation coefficient of Equation (2) to the following weighted correlation coefficient:

$$
\begin{aligned}
& \rho_{w}(A(t), B(t))= \\
& \sum_{k=1}^{q} \omega\left(t_{k}\right) \frac{\sum_{j=1}^{n} w_{j}\left[\mu_{A}\left(t_{k}, x_{j}\right) \mu_{B}\left(t_{k}, x_{j}\right)+\tau_{A}\left(t_{k}, x_{j}\right) \tau_{B}\left(t_{k}, x_{j}\right)+v_{A}\left(t_{k}, x_{j}\right) v_{B}\left(t_{k}, x_{j}\right)\right]}{\left(\sqrt{\sum_{j=1}^{n} w_{j}\left[\left(\mu_{A}\left(t_{k}, x_{j}\right)\right)^{2}+\left(\tau_{A}\left(t_{k}, x_{j}\right)\right)^{2}+\left(v_{A}\left(t_{k}, x_{j}\right)\right)^{2}\right]}\right.} \\
& \sqrt{\sum_{j=1}^{n} w_{j}\left[\left(\mu_{B}\left(t_{k}, x_{j}\right)\right)^{2}+\left(\tau_{B}\left(t_{k}, x_{j}\right)\right)^{2}+\left(v_{B}\left(t_{k}, x_{j}\right)\right)^{2}\right]}
\end{aligned}
$$

when $w_{j}=1 / n(j=1,2, \ldots, n)$ and $\omega\left(t_{k}\right)=1 / q(k=1,2, \ldots, q)$, Equation (3) reduces to Equation (2).

Theorem 2. The correlation coefficient $\rho_{w}(A(t), B(t))$ also satisfies the following three properties:

(P1) $0 \leq \rho_{w}(A(t), B(t)) \leq 1$;

(P2) $\rho_{w}(A(t), B(t))=1$ if $A(t)=B(t)$;

(P3) $\rho_{w}(A(t), B(t))=\rho_{w}(B(t), A(t))$.

By the previous similar proof method in Theorem 1, we can prove the properties (P1)-(P3) (omitted).

\section{Correlation Coefficient for Multiple Attribute Decision-Making}

In this section, we apply the weighted correlation coefficient of DSVNMs to multiple attribute decision-making problems with DSVNM information.

For a multiple attribute decision-making problem with DSVNM information, let $G=\left\{g_{1}, g_{2}, \ldots, g_{m}\right\}$ be a discrete set of alternatives, $X=\left\{x_{1}, x_{2}, \ldots, x_{n}\right\}$ be a set of attributes, and $t=\left\{t_{1}, t_{2}, \ldots, t_{q}\right\}$ be a time sequence. If the decision makers provide an evaluation value for the alternative $g_{i}(i=1,2, \ldots, m)$ regarding the attribute $x_{j}(j=1,2, \ldots, n)$ at a time $t_{k}(k=1,2, \ldots, q)$, the evaluation value can be represented by the form of a DSVNME $d_{i j}(t)=\left\langle\left(\mu_{i}\left(t_{1}, x_{j}\right), \mu_{i}\left(t_{2}, x_{j}\right), \ldots, \mu_{i}\left(t_{q}, x_{j}\right)\right),\left(\tau_{i}\left(t_{1}, x_{j}\right), \tau_{i}\left(t_{2}, x_{j}\right), \ldots, \tau_{i}\left(t_{q}, x_{j}\right)\right)\right.$, $\left.\left(v_{i}\left(t_{1}, x_{j}\right), v_{i}\left(t_{2}, x_{j}\right), \ldots, v_{i}\left(t_{q}, x_{j}\right)\right)\right\rangle(j=1,2, \ldots, n ; i=1,2, \ldots, m)$. Therefore, we can elicit a DSVNM decision matrix $D(t)=\left(d_{i j}(t)\right)_{m \times n}$, where $d_{i j}(t)(i=1,2, \ldots, m ; j=1,2, \ldots, n)$ is in a DSVNME form.

In multiple attribute decision-making problems, the ideal alternative is used to help the identification of the best alternative in the decision set. Therefore, we define each ideal DSVNME $d_{j}^{*}(t)=\left\langle\left(\mu^{*}\left(t_{1}, x_{j}\right), \mu^{*}\left(t_{2}, x_{j}\right), \ldots, \mu^{*}\left(t_{q}, x_{j}\right)\right),\left(\tau^{*}\left(t_{1}, x_{j}\right), \tau^{*}\left(t_{2}, x_{j}\right), \ldots, \tau^{*}\left(t_{q}, x_{j}\right)\right),\left(v^{*}\left(t_{1}, x_{j}\right), v^{*}\left(t_{2}, x_{j}\right), \ldots\right.\right.$, $\left.\left.v^{*}\left(t_{q}, x_{j}\right)\right)\right\rangle=\langle(1,1, \ldots, 1),(0,0, \ldots, 0),(0,0, \ldots, 0)\rangle(j=1,2, \ldots, n)$ in the ideal solution (ideal alternative) $g^{*}(t)=\left\{\left\langle x_{j}, d_{j}^{*}(t)\right\rangle \mid t_{k} \in t, x_{j} \in X\right\}(k=1,2, \ldots, q ; j=1,2, \ldots, n)$.

Assume that the weighting vector of attributes for the different importance of each attribute $x_{j}(j=1,2, \ldots, n)$ is given by $\boldsymbol{w}=\left(w_{1}, w_{2}, \ldots, w_{n}\right)^{\mathrm{T}}$ with $w_{j} \geq 0, \sum_{j=1}^{n} w_{j}=1$ and the time weighting vector for the different importance of each time $t_{k}(k=1,2, \ldots, q)$ is given by $\omega(t)=\left(\omega\left(t_{1}\right), \omega\left(t_{2}\right), \ldots\right.$, $\left.\omega\left(t_{q}\right)\right)^{\mathrm{T}}$ with $\omega\left(t_{k}\right) \geq 0$ and $\sum_{k=1}^{q} \omega\left(t_{k}\right)=1$.

Then, we utilize the weighted correlation coefficient for multiple attribute decision-making problems with DSVNM information.

The weighted correlation coefficient between an alternative $g_{i}(t)(i=1,2, \ldots, m)$ and the ideal solution $g^{*}(t)$ is calculated by use of the following formula:

$$
\rho_{w}\left(g_{i}(t), g^{*}(t)\right)=\sum_{k=1}^{q} \omega\left(t_{k}\right) \frac{\sum_{j=1}^{n} w_{j}\left[\mu_{i}\left(t_{k}, x_{j}\right)\right]}{\sqrt{\sum_{j=1}^{n} w_{j}\left[\left(\mu_{i}\left(t_{k}, x_{j}\right)\right)^{2}+\left(\tau_{i}\left(t_{k}, x_{j}\right)\right)^{2}+\left(v_{i}\left(t_{k}, x_{j}\right)\right)^{2}\right]}}
$$

The bigger the value of $\rho_{w}\left(g_{i}(t), g^{*}(t)\right)$, the better the alternative $g_{i}$. Then, we rank the alternatives and select the best one(s) according to the values of weighted correlation coefficients. 


\section{Practical Example}

A practical example about investment alternatives for a multiple attribute decision-making problem adapted from Ye [8] is used to demonstrate the applications of the proposed decision-making method under a DSVNM environment. There is an investment company, which wants to invest a sum of money in the best option. There is a panel with four possible alternatives to invest the money: (1) $g_{1}$ is a car company; (2) $g_{2}$ is a food company; (3) $g_{3}$ is a computer company; (4) $g_{4}$ is an arms company. The investment company must take a decision according to the three attributes: (1) $x_{1}$ is the risk factor; (2) $x_{2}$ is the growth factor; (3) $x_{3}$ is the environmental factor. Let us consider the evaluations of the alternatives on the attributes given by decision makers or experts in the time sequence $t=\left\{t_{1}, t_{2}, t_{3}\right\}$. Assume that the weighting vector of the attributes is given by $w=(0.35,0.25$, $0.40)^{\mathrm{T}}$ and the weighting vector of times is given by $\omega(t)=(0.25,0.35,0.40)^{\mathrm{T}}$. The four possible alternatives of $g_{i}(i=1,2,3,4)$ regarding the three attributes of $x_{j}(j=1,2,3)$ are evaluated by decision makers, and then the evaluation values are represented by using DSVNMEs, which are given as the following DSVNM decision matrix $D(t)$ :

$$
\begin{aligned}
& D(t)=\left[\begin{array}{l}
\langle(0.4,0.5,0.3),(0.1,0.2,0.3),(0.3,0.2,0.3)\rangle \\
\langle(0.6,0.4,0.5),(0.1,0.1,0.2),(0.1,0.2,0.3)\rangle \\
\langle(0.4,0.2,0.3),(0.2,0.1,0.2),(0.2,0.3,0.3)\rangle \\
\langle(0.7,0.6,0.8),(0.1,0.0,0.0),(0.1,0.1,0.1)\rangle
\end{array}\right. \\
& \langle(0.4,0.5,0.3),(0.1,0.2,0.2),(0.2,0.3,0.3)\rangle \\
& \langle(0.5,0.6,0.7),(0.1,0.1,0.1),(0.1,0.2,0.2)\rangle \\
& \langle(0.4,0.5,0.6),(0.1,0.2,0.2),(0.4,0.2,0.3)\rangle \\
& \langle(0.6,0.5,0.7),(0.1,0.2,0.1),(0.2,0.3,0.2)\rangle \\
& \langle(0.2,0.3,0.2),(0.2,0.2,0.2),(0.4,0.3,0.5)\rangle] \\
& \langle(0.5,0.6,0.7),(0.2,0.1,0.2),(0.1,0.2,0.2)\rangle \\
& \langle(0.6,0.5,0.6),(0.3,0.2,0.3),(0.2,0.2,0.3)\rangle \text {. } \\
& \langle(0.4,0.5,0.4),(0.3,0.2,0.2),(0.2,0.1,0.2)\rangle]
\end{aligned}
$$

Then, the developed approach is utilized to give the ranking order of the alternatives and the best one(s).

By applying Equation (4), we can obtain the values of the weighted correlation coefficient between each alternative and the ideal alternative as follows:

$\rho_{w}\left(g_{1}(t), g^{*}(t)\right)=0.6285, \rho_{w}\left(g_{2}(t), g^{*}(t)\right)=0.9122, \rho_{w}\left(g_{3}(t), g^{*}(t)\right)=0.7758$ and $\rho_{w}\left(g_{4}(t), g^{*}(t)\right)=0.9025$.

According to the above values of weighted correlation coefficients, we can give the ranking order of the four alternatives: $A_{2} \succ A_{4} \succ A_{3} \succ A_{1}$, which is in accordance with the one of [8]. Therefore, the alternative $A_{2}$ is the best choice.

The example clearly indicates that the proposed decision-making method is simple and effective under the DSVNM environment, based on the weighted correlation coefficient of DSVNMs for dealing with multiple attribute decision-making problems with DSVNM information, since such a decision-making method can represent and handle the dynamic evaluation data given by experts or decision makers at different time intervals, while existing various neutrosophic decision-making methods cannot do this.

\section{Conclusions}

Based on dynamic information collected from different time intervals in some real situations, this paper proposed a DSVNM to express dynamic information and the operational relations of DSVNMs. The DSVNM is a dynamic set encompassing a time sequence, where its truth-membership degrees, indeterminacy-membership degrees, and falsity-membership degrees are represented by time sequences. Therefore, DSVNM has desirable characteristics and advantages of its own for handling 
dynamic problems according to a time sequence in real applications, whereas existing neutrosophic sets cannot deal with them.

Then, we proposed the correlation coefficient of DSVNMs and weighted correlation coefficient of DSVNMs and investigated their properties. Based on the weighted correlation coefficient of DSVNMs, the multiple attribute decision-making method was proposed under a DSVNM environment, in which the evaluated values of alternatives regarding attributes take the form of DSVNMEs. Through the weighted correlation coefficient between each alternative and the ideal alternative, one can rank alternatives and choose the best one(s). Finally, a practical example about investment alternatives was given to demonstrate the practicality and effectiveness of the developed approach. The proposed method is simple and effective under the DSVNM decision-making environment.

In the future, we shall extend DSVNMs to interval/bipolar neutrosophic sets and develop dynamic interval/bipolar neutrosophic decision-making and medical diagnosis methods in different time intervals.

Acknowledgments: This paper was supported by the National Natural Science Foundation of China (No. 71471172).

Conflicts of Interest: The author declares no conflict of interest.

\section{References}

1. Smarandache, F. A Unifying Field in Logics: Neutrosophy. Neutrosophic Probability, Set and Logic; American Research Press: Rehoboth, MA, USA, 1999.

2. Zadeh, L.A. Fuzzy Sets. Inf. Control 1965, 8, 338-353. [CrossRef]

3. Atanassov, K. Intuitionistic fuzzy sets. Fuzzy Sets Syst. 1986, 20, 87-96. [CrossRef]

4. Atanassov, K.; Gargov, G. Interval valued intuitionistic fuzzy sets. Fuzzy Sets Syst. 1989, 31, 343-349. [CrossRef]

5. Wang, H.; Smarandache, F.; Zhang, Y.Q.; Sunderraman, R. Interval Neutrosophic Sets and Logic: Theory and Applications in Computing; Hexis: Phoenix, AZ, USA, 2005.

6. Wang, H.; Smarandache, F.; Zhang, Y.Q.; Sunderraman, R. Single valued neutrosophic sets. Multisp. Multistruct. 2010, 4, 410-413.

7. Chi, P.P.; Liu, P.D. An extended TOPSIS method for the multiple attribute decision-making problems based on interval neutrosophic sets. Neutrosophic Sets Syst. 2013, 1, 63-70.

8. Ye, J. Multicriteria decision-making method using the correlation coefficient under single-valued neutrosophic environment. Int. J. Gen. Syst. 2013, 42, 386-394. [CrossRef]

9. Liu, P.D.; Chu, Y.C.; Li, Y.W.; Chen, Y.B. Some generalized neutrosophic number Hamacher aggregation operators and their application to group decision-making. Int. J. Fuzzy Syst. 2014, 16, 242-255.

10. Liu, P.D.; Wang, Y.M. Multiple attribute decision-making method based on single valued neutrosophic normalized weighted Bonferroni mean. Neural Comput. Appl. 2014, 25, 2001-2010. [CrossRef]

11. Liu, P.D.; Tang, G.L. Some power generalized aggregation operators based on the interval neutrosophic numbers and their application to decision-making. J. Intell. Fuzzy Syst. 2016, 30, 2517-2528. [CrossRef]

12. Liu, P.D.; Wang, Y.M. Interval neutrosophic prioritized OWA operator and its application to multiple attribute decision-making. J. Syst. Sci. Complex. 2016, 29, 681-697. [CrossRef]

13. Liu, P.D. The aggregation operators based on Archimedean $\mathrm{t}$-conorm and $\mathrm{t}$-norm for the single valued neutrosophic numbers and their application to decision-making. Int. J. Fuzzy Syst. 2016, 18, 849-863. [CrossRef]

14. Şahin, R.; Küçük, A. Subsethood measure for single valued neutrosophic sets. J. Intell. Fuzzy Syst. 2015, 29, 525-530. [CrossRef]

15. Şahin, R.; Liu, P.D. Maximizing deviation method for neutrosophic multiple attribute decision-making with incomplete weight information. Neural Comput. Appl. 2016, 27, 2017-2029. [CrossRef]

16. Şahin, R. Cross-entropy measure on interval neutrosophic sets and its applications in multicriteria decision-making. Neural Comput. Appl. 2015. [CrossRef]

17. Şahin, R.; Liu, P.D. Possibility-induced simplified neutrosophic aggregation operators and their application to multicriteria group decision-making. J. Exp. Theor. Artif. Intell. 2016. [CrossRef]

18. Ye, J. Single valued neutrosophic minimum spanning tree and its clustering method. J. Intell. Syst. 2014, 23, 311-324. [CrossRef] 
19. Ye, J. Clustering methods using distance-based similarity measures of single-valued neutrosophic sets. J. Intell. Syst. 2014, 23, 379-389. [CrossRef]

20. Cheng, H.D.; Guo, Y. A new neutrosophic approach to image thresholding. New Math. Nat. Comput. 2008, 4, 291-308. [CrossRef]

21. Guo, Y.; Cheng, H.D. New neutrosophic approach to image segmentation. Pattern Recognit. 2009, 42, 587-595. [CrossRef]

22. Guo, Y.; Sengur, A.; Ye, J. A novel image thresholding algorithm based on neutrosophic similarity score. Measurement 2014, 58, 175-186. [CrossRef]

23. Maji, P.K. Neutrosophic soft set. Ann. Fuzzy Math. Inf. 2012, 5, 157-168.

24. Maji, P.K. Neutrosophic soft set approach to a decision-making problem. Ann. Fuzzy Math. Inf. 2013, 3, 313-319.

25. Sahin, R.; Kucuk, A. Generalized neutrosophic soft set and its integration to decision-making problem. Appl. Math. Inf. Sci. 2014, 8, 2751-2759. [CrossRef]

26. Ye, J. Multiple-attribute decision-making method under a single-valued neutrosophic hesitant fuzzy environment. J. Intell. Syst. 2015, 24, 23-36. [CrossRef]

27. Şahin, R.; Liu, P.D. Correlation coefficient of single-valued neutrosophic hesitant fuzzy sets and its applications in decision-making. Neural Comput. Appl. 2016. [CrossRef]

28. Liu, P.D.; Shi, L.L. The generalized hybrid weighted average operator based on interval neutrosophic hesitant set and its application to multiple attribute decision-making. Neural Comput. Appl. 2015, 26, 457-471. [CrossRef]

29. Ye, J. Some aggregation operators of interval neutrosophic linguistic numbers for multiple attribute decision-making. J. Intell. Fuzzy Syst. 2014, 27, 2231-2241.

30. Ye, J. An extended TOPSIS method for multiple attribute group decision-making based on single valued neutrosophic linguistic numbers. J. Intell. Fuzzy Syst. 2015, 28, 247-255.

31. Ye, S.; Fu, J.; Ye, J. Medical diagnosis using distance-based similarity measures of single valued neutrosophic multisets. Neutrosophic Sets Syst. 2015, 7, 47-52.

32. Peng, J.J.; Wang, J.Q.; Wu, X.H.; Wang, J.; Chen, X.H. Multivalued neutrosophic sets and power aggregation operators with their applications in multi-criteria group decision-making problems. Int. J. Comput. Intell. Syst. 2015, 8, 345-363. [CrossRef]

33. Liu, P.D.; Zhang, L.L.; Liu, X.; Wang, P. Multi-valued neutrosophic number Bonferroni mean operators and their application in multiple attribute group decision-making. Int. J. Inf. Technol. Decis. Mak. 2016, 15, 1181-1210. [CrossRef]

34. Broumi, S.; Deli, I.; Smarandache, F. N-valued Interval Neutrosophic Sets and Their Application in Medical Diagnosis; Critical Review; Center for Mathematics of Uncertainty, Creighton University: Omaha, NE, USA, 2015; Volume 10, pp. 46-69.

35. Deli, I.; Broumi, S.; Smarandache, F. On neutrosophic refined sets and their applications in medical diagnosis. J. New Theory 2015, 6, 88-98.

36. Broumi, S.; Deli, I. Correlation measure for neutrosophic refined sets and its application in medical diagnosis. Palest. J. Math. 2016, 5, 135-143.

37. Şubaş, Y.; Deli, I. Bipolar neutrosophic refined sets and their applications in medical diagnosis. In Proceedings of the International Conference on Natural Science and Engineering (ICNASE'16), Kilis, Turkey, 19-20 March 2016; pp. 1121-1132.

38. Liu, P.D.; Teng, F. Multiple attribute decision-making method based on normal neutrosophic generalized weighted power averaging operator. Int. J. Mach. Learn. Cybern. 2015. [CrossRef]

39. Liu, P.D.; Li, H.G. Multiple attribute decision-making method based on some normal neutrosophic Bonferroni mean operators. Neural Comput. Appl. 2017, 28, 179-194. [CrossRef]

(C) 2017 by the author. Licensee MDPI, Basel, Switzerland. This article is an open access article distributed under the terms and conditions of the Creative Commons Attribution (CC BY) license (http:/ / creativecommons.org/licenses/by/4.0/). 